\title{
México: una democracia entre amarguras y esperanzas. Entrevista al sociólogo Sergio Zermeño
}

\author{
Nicolás Dip \\ Facultad de Humanidades y Ciencias de la Educación \\ Universidad Nacional de La Plata / CONICET, Argentina \\ nicolasdip88@gmail.com
}

Ensayos amargos sobre mi pais. Del 68 al nuevo régimen, cincuenta años de ilusiones (2018) es el último libro del investigador mexicano Sergio Zermeño. Si del arte de titular se trata, el trabajo que nos ocupa merece un comentario aparte, ya que sintetiza una extensa y reconocida trayectoria política e intelectual plagada de sensaciones encontradas. Es que conversar con Zermeño es indagar en los últimos cincuenta años de la historia mexicana, con sus turbulencias sociales, políticas y culturales. Diálogo que se enriquece porque sus reflexiones son impulsadas en su doble condición de protagonista e intérprete. Desde sus primeros pasos como sociólogo en la Universidad Nacional Autónoma de México (UNAM), Zermeño no estuvo ajeno a las encrucijadas de su sociedad. A esto suma una formación que lo llevó a estudiar con Alain Touraine en la Sorbona de París y convertirse en la actualidad en uno de los principales referentes del Instituto de Investigaciones Sociales de la UNAM. Trayectoria que se materializa en un gran número de libros y artículos donde existe un esfuerzo persistente por enlazar los saberes universitarios con las problemáticas del entorno social y la historia de su país.

En esta extensa entrevista a Zermeño reconstruimos su itinerario y los núcleos temáticos de sus principales obras con la finalidad de analizar un conjunto de cuestiones que interpelan a la sociedad, la cultura y la política mexicana, como las discusiones pendientes que dejaron los cincuenta años del movimiento de protesta de 1968, el camino errático de la izquierda y su asimilación con la cultura priista, las limitaciones del zapatismo y los desafíos que enfrentan los intelectuales y las ciencias sociales en la actualidad. Todos estos temas no sólo son abordados en profundidad, sino también cuestionados a la luz del inédito proceso político que vive México, con la elección de Andrés Manuel López Obrador como presidente y la reciente asunción de su gobierno bajo las banderas de la "Cuarta Transformación", que enarbola el Movimiento Regeneración Nacional, más conocido como Morena.

- En 1968 estudiabas sociología en la UNAM y formabas parte del movimiento de protesta estudiantil, donde te desempeñabas como inexperto editor de $\mathrm{La}$ Gaceta del CNH, el medio de comunicación que se creó a instancias del Consejo Nacional de Huelga. Pero una década más tarde, te convertiste de protagonista a intérprete, ya que tu doctorado en la Sorbona de París culminó en una tesis dirigida por Alain Touraine que en la actualidad es un libro clásico en la temática: México: una democracia utópica. El movimiento estudiantil del 68 (1978). Tu trabajo fue publicado el cumplirse una década del 68 y el año pasado se celebró el cincuentenario, en todo este recorrido y en tu doble condición de protagonistaintérprete, ¿qué avances, retrocesos y deudas pendientes visualizás en la bibliografía sobre el 68?

- Yo me he dado cuenta de un gran hueco en la reflexión de mi generación sobre lo que nos sucedió. Es la falta de una perspectiva académica y conceptual de amplio espectro, bastante más abstracta de lo que tenemos como material. Poseemos una inmensa cantidad de testimonios, crónicas, cronologías y momentos muy ricos. Pero escasea una consideración, por ejemplo, de que si lo que hicimos en el 68 era nuevo o era una extensión de nuestra propia cultura priista-marxista. Eso es muy interesante, cómo el priismo y el marxismo se amalgamaron en el sentido de la búsqueda de la obtención del Estado como instrumento del cambio social 
y de un cambio cualitativo estructural. Ya éramos dependientes de la idea de que el Estado es importantísimo. Teníamos una cultura estatal muy poderosa. La Revolución y el cardenismo nos dieron una idea de Estado muy fuerte en toda nuestra concepción. Luego, el impacto del marxismo en los años 60 no hace más que vestir de un modo bonito una concepción de "asalto al Palacio de Invierno" para construir desde ahí otra sociedad. El marxismo de esa época y nuestras imágenes del leninismo, del trotskismo y otras corrientes era la de dirigir a la sociedad. La idea de dirección que fue tan nociva y dañina. En ese camino de buscar colocarnos arriba para luego redimir abajo se perdió todo el mundo. La llamada izquierda mexicana fue desde entonces una batalla por los puestos de dirección y de poder. Esto que estoy diciendo casi nadie lo dijo. No digo que yo sea diferente, simplemente me alejé a estudiar a Francia y estuve bajo la batuta de un director de tesis que no admitía tonterías, como Alain Touraine. Uno no podía llegar y decirle: "Fue imposible para el movimiento la toma del Estado". En ese momento te paraba y te preguntaba: "¿qué está usted diciendo? ¿Eso era la conciencia de época de los estudiantes? Piense bien en lo que está diciendo". Creo que faltó esa distancia. A mí por fortuna me la dio Alain Touraine y es mérito de él haber hecho las preguntas correctas: "Zermeño, ¿cuál era su adversario? ¿Contra qué estaban luchando? ¿Quiénes eran ustedes?”. Es la tríada IOT: identité, opposition, totalité. Identidad: quiénes éramos. Oposición: contra qué luchábamos. Totalidad: en qué campo del conflicto se establecía la adversidad. Touraine me preguntaba: “ ¿Tenían ustedes elementos para pensar una sociedad nueva o estaban metidos en medio de su tarabilla priista-marxista y no salían de ahí?” A mi entender, pocos siguieron ese tipo de interrogantes y quienes hicieron la historia del movimiento estudiantil fueron básicamente los dirigentes. A través de entrevistas, escritos, discursos y mesas redondas cada uno de los dirigentes fue haciendo una historia. Es la historia oficial del movimiento del 68. Pero entre los dirigentes no había ningún intelectual alto, quizás Marcelino Perelló. Era un español muy lúcido que llegó a México. $\mathrm{Ni}$ siquiera fue preso político porque él se escabulló muy rápido. Eran gente de ciencias duras, de biología y de físico-matemáticas. No hay ningún sociólogo importante entre los dirigentes del 68.

- Entonces, ętu diagnóstico es que alrededor de tu generación y de los dirigentes del 68 se erigió una lectura oficial a la cual le falta distancia y una construcción teórica más amplia para abordar el tema?

- Sí, todos ellos reconstruyeron su papel, su momento, la situación, desde dónde dispararon el 2 de octubre y qué traiciones se cometieron en el nivel del Consejo Nacional de Huelga. Una historia muy pragmática y muy cotidiana. El libro más vendido del 68 mexicano es un libro de testimonios: La Noche de Tlatelolco (1971) de Elena Poniatowska. Por los 50 años lo volví a leer y dije "maravilloso", porque tiene partes lindísimas, pero no deja de ser un libro de relatos. El que sí tiene cierta distancia es Luis González de Alba con su novela Los días y los años (1971). Aunque él era un psicólogo, estudiaba psicología en la Facultad de Filosofía y Letras de la UNAM, no tiene una teoría un poco más avanzada.

- Y en las investigaciones de generaciones más jóvenes, ¿existe algún trabajo o escrito en relación al 68 que te haya llamado la atención en los últimos tiempos?

- Me parece que ahora hay una serie de compañeros que están estudiando el movimiento del 68 con una metodología que hace énfasis en el cambio en las mentalidades y en las emociones de la gente de aquel momento. Tengo la impresión de que hay una psicología social poderosa buscando en el 68 cambios mentales, pero no hay una sociología poderosa que lo coloque dentro de un contexto social e histórico fuerte. Por decirlo así: Alain Touraine hace un estudio sobre el 68' francés y lo llamó El Movimiento de Mayo o el Comunismo Utópico (1969). Me influyó en el título de mi trabajo porque él decía: "lo que los estudiantes decían que querían, no eran lo que querían. Ellos querían otra cosa y por eso ya estaban expresando el cambio de una mentalidad, de una concepción del entorno y de su historia, aunque no encontraban todavía los elementos. Ellos no querían aliarse a la clase obrera para cambiar tal cosa. Ellos querían una nueva sociedad en términos culturales de tal tipo". Ese tipo de razonamiento a lo Touraine o Escuela de Frankfurt no lo encuentro estudiando el movimiento estudiantil. Yo veo ese hueco, pero es verdad que estoy desactualizado en relación a los compañeros más jóvenes que abordan el 68 desde las emociones, las mentalidades, la memoria y desde 
ángulos que no termino de entender muy bien. Tengo que actualizarme porque no estoy entendiendo bien qué riqueza van a sacar a través de esa metodología... A lo mejor mucha.

- En México: una democracia utópica, como en tu último libro que también publicaste con Siglo XXI, titulado Ensayos amargos sobre mi país. Del 68 al nuevo régimen, cincuenta años de ilusiones, sostenés una lectura sobre el movimiento estudiantil mexicano de los años sesenta, al que diferenciás de otras partes del mundo por una primacía de la política que lo llevó a la pérdida de sus contenidos culturales, a estructuras organizativas jerárquicas y a una ajenidad hacia los problemas de la universidad y la educación superior. En otros países de Latinoamérica existe un conjunto de visiones similares que comparten exmilitantes de los años sesenta y setenta que abordaron retrospectivamente su historia, luego de convertirse en reconocidos intelectuales. Más allá de los matices y sus itinerarios personales, trabajos como los de Oscar Terán (1991) y Beatriz Sarlo (2001) en el caso argentino, o el de Manuel Antonio Garretón (1985) en el chileno, sostienen una hipótesis similar: las formas y contenidos políticos que transitaron los grupos radicalizados del movimiento estudiantil y la universidad no hicieron más que disolver las cuestiones culturales e intelectuales. Cincuenta años después, ¿̇cuáles son los puntos que te hacen reafirmar esta hipótesis de la disolución de los ámbitos específicos por la primacía de la política? ¿Se pueden encontrar matices e intentos de discusión sobre proyectos de universidad en el movimiento estudiantil de 1968? En tu último libro enfatizás que el intelectual de izquierda José Revueltas insistió mucho respecto a los problemas internos de la institución universitaria durante esos años. ${ }^{1}$

- Creo que el movimiento universitario mexicano del 68 pudo haber derivado en una reforma de la universidad muy importante, porque teníamos una universidad muy atrasada y muy autoritaria. Increíblemente se quedó así hasta hoy. La estructura de autoridad del gobierno de la universidad es maravillosa, muestra un autoritarismo... el PRI se cayó, pero la estructura de autoridad de la UNAM se mantuvo y se mantiene incólume. El 68 pudo haber derivado en una reforma universitaria importante porque en el fondo sí había una protesta que se quedó callada en torno a la autogestión y el cogobierno universitario; a la participación mucho mayor de los estudiantes en el contenido de las materias y en los órganos de autoridad. El tema estaba planteado, a tal grado que en la Facultad de Arquitectura en los años posteriores al 68 se desarrolla el experimento del autogobierno universitario y ahí se genera una discusión muy fuerte en torno a cómo debía funcionar la universidad. En esa experiencia se reforma la Facultad de Arquitectura y se divide en dos. El autogobierno era la mitad progresista, donde el profesor tenía una función muy poco autoritaria. Y la otra mitad era la vieja arquitectura, con toda la estructura vertical del profesor. El experimento del autogobierno de la Facultad de Arquitectura es interesante, pero la sangre destruyó todo. El 2 de octubre es una cosa tan brutal que dejas de pensar en la universidad, dejas de pensar en la cultura, dejas de pensar en todo y te metes en un hoyo negro, inmundo de venganza y de autodestrucción. Fue muy duro y tremendo el 2 de octubre. Entonces, creo que eso explica ese hueco, la guerrilla que surge en los años posteriores, más sangre, más autoritarismo, menos cultura y más brutalidad. Acá en México se clausuró todo de un plumazo. Entonces no pensamos la universidad en los términos que pensó Argentina en la Reforma de 1918 y en décadas posteriores, o en Chile durante la Unidad Popular de Salvador Allende, donde había intelectuales pensando qué debía ser la universidad. Yo me fui a Francia en julio del 72, pero antes fui a un Congreso de Sociología Latinoamericana muy importante que se hizo en Chile. Fue maravillo llegar a Santiago y ver la experiencia chilena de gobierno. Aunque después ahí ocurrió la represión a la enésima potencia de lo que fue en México.

- ¿Y a Revueltas se lo tuvo en cuenta durante el 68 en los temas universitarios?

Se lo tuvo siempre en cuenta. Yo pienso que mucho más como un héroe que como un intelectual. Por eso creo que no se leyó mucho a Revueltas en ese momento. A Revueltas se lo leía mucho más en dos cosas: su Ensayo sobre un proletariado sin cabeza (1962) y sus novelas como El Apando (1969). Pero no en su reflexión de la temática universitaria. Él acompañó e integró el movimiento del 68. Pensaba desde la Facultad de Filosofía y Letras. Ahí dormía y desarrollaba su idea de autogobierno y de comunidad universitaria con 
una influencia muy maoísta. Estábamos frente a la Revolución Cultural China. Desde esta perspectiva, Revueltas se planteó una reforma de la universidad de otra manera, aunque no tuvo repercusión importante en el movimiento del 68. Una izquierda cultural profunda lo reivindica, pero en el momento no tuvo una centralidad decisiva.

- En Ensayos amargos sobre mi país, realizás un ejercicio de sociología política sobre la cambiante trayectoria de la izquierda mexicana en el contexto de la compleja cultura política del país. Señalás que a la misma hay que comprenderla en el marco de dos pilares de la cultura política de México que se retrotraen a la Revolución de 1910, e incluso llegás a indicar que desde antes: la fascinación por el vértice y el desafío de articular fuerzas disímbolas. A partir de este enfoque, delimitás cuatro grandes acumulaciones que interpelaron o involucraron de alguna manera a la izquierda, desde el llamado callista a la unidad de todas las fuerzas que remató en la creación del Partido de Estado y en la gesta nacionalista del cardenismo, pasando por el Movimiento de Liberación Nacional en pleno auge de la Revolución Cubana, la irrupción del Partido de la Revolución Democrática (PRD) encabezado por el hijo del general Cárdenas, hasta la actual constitución de Morena y el triunfo presidencial de Andrés Manuel López Obrador. En este marco, ¿cuáles son los desafíos que tiene por delante la cuarta condensación que recién está dando sus primeros pasos en el gobierno?

- Pienso que esta cuarta condensación tiene dos posibilidades: repetir la historia de sus antecesoras o no repetirla. Esa historia es una estructura muy clásica e inútil. Juntémonos para tener el poder del Estado y desde ahí reformar a la sociedad. Pero en ese "juntémonos", como quienes se juntan son tan diferentes, si no obtienen el poder del Estado caen en serios problemas. Por eso la primera condensación y la última tienen algo diferente que la segunda y la tercera. La de Calles-Cárdenas y la de ahora de López Obrador poseen al Estado nacional. Eso es muy interesante porque Cuauhtémoc con el PRD no tuvo ese poder, entonces fue incapaz de mantener sus corrientes juntas. Y la historia del perredismo como gobierno de la Ciudad de México, del Distrito Federal, es increíble. La cantidad de bandas que estaban posesionándose de la administración pública del Distrito Federal. Es una historia de horror entre 14 pandillas y dirigencias matándose para conseguir una delegación, ahora alcaldía. Una degeneración ética extrema de lo que fueron nuestros valores. En 1997 Cárdenas gana el gobierno de la ciudad y tiene que apoyarse en toda la gente que conformó el PRD. Su antecesor, el Frente Democrático Nacional, se funda en 1988 en contra de la elección de Carlos Salinas de Gortari y a favor de Cuauhtémoc. Se produce un gran fraude ahí. El PRD se forma al año siguiente con muchas corrientes internas y luego con la aparición del zapatismo vienen una serie de golpes muy grandes a la estructura priista. Entonces, salen del PRI una cantidad de cuadros que se van al PRD. La cantidad de corrientes distintas y disímbolas que forman el PRD ya en los años 90 es brutal. Cuando ganan el gobierno de la Ciudad de México en las elecciones de 1997, Cárdenas tiene que darle cabida a toda la gente que lo impulsó y entonces el gobierno se vuelve casi imposible. Como no tiene el gobierno federal, sino nada más el de la ciudad, no tiene el poder para disciplinar a todas esas corrientes. Lo interesante sería preguntarse si hoy López Obrador, teniendo el poder del Estado Federal, posee al mismo tiempo -yo creo que sí- el poder y la fuerza para disciplinar esa brutal mezcolanza que está detrás de Morena. Hice un artículo que se llama: "Cuarta Transformación, all together now". Open house, ¿no? Vengan todos. Entonces es muy interesante lo que viene. $\mathrm{O}$ se va por una especie de reproducción del fracaso del PRD como gobierno de la Ciudad de México o el proceso realmente genera un líder y un principio estatal poderoso que realmente sea eficaz hacia adelante. Pero esa eficacia, ¿cuál debe ser? Ese es otro tema. Nosotros pensamos que debe ser una eficacia de reconstrucción social en lo social, no de reconstrucción de alianzas en lo político. El peligro de la reconstrucción de alianzas en lo político es inminente. Toda la discusión hoy en Morena es algo así: "¿está bien que Víctor Villalobos sea el secretario de Agricultura del gobierno en vez de los líderes populares y de izquierda?". Ahí está la discusión. Morena debe tener mucho cuidado porque tiene ese peligro y está infiltrado por el cucarachero que salió del PRD. Hay que estar atentos porque estamos bregando con una cultura ética y política verdaderamente muy desvirtuada. 
- Teniendo en cuenta estos recorridos conflictivos y erráticos, èla izquierda mexicana puede reelaborar la lectura de su pasado desde una perspectiva autocrítica?

- Creo que no. Tiene una muy baja autocrítica y una baja lectura de la experiencia universal latinoamericana y europea como para entender a dónde van los ensayos de reconstrucción social. La propia izquierda no tiene canteras de capacidad y sinceridad para hacerlo. Es demasiado dolorosa la historia de la izquierda mexicana como para que la misma izquierda haga un buen análisis de su propia trayectoria. Estaba Paul Ricoeur haciendo una historia del comunismo en México. Eso es más fácil porque finalmente el comunismo tiene una cierta coherencia, pero un estudio de la izquierda mexicana en serio es verdaderamente desgarrador. Yo así lo veo, francamente es muy triste la cultura política mexicana de izquierda y su práctica.

- ¿Y ve intelectuales o académicos jóvenes que estén en ese camino?

- No veo quién. A lo mejor se necesita ser muy joven y tener una cierta distancia. No ser hijo de un comunista. Los comunistas hijos de comunistas emigrados españoles son los más ilustres y serios intelectualmente. Ellos no lo van a hacer. No veo a Elvira Concheiro haciendo una historia desgarradora de la izquierda mexicana, ni tampoco a Luciano Concheiro y menos a Adolfo Gilly. Son personas que dependen de su prestigio frente a la izquierda. Ahorita me gustaría marcarle el teléfono a John Womack Jr., que hizo la historia del zapatismo (1969), con la distancia de un académico extranjero, sobre todo anglosajón, que tiene una distancia mayor, aunque unos conceptos no tan buenos. Pero la historia de la izquierda no sé quién pueda hacerla. Ese es un trabajo pendiente que alguien tiene que hacer y no va a surgir de la izquierda misma.

- A tu entender, el gobierno de Morena llega tarde pero a la vez es una posibilidad de reiniciar una nueva corriente que sea capaz de enmendar los vicios y desvíos burocráticos de los ciclos latinoamericanos precedentes, los cuales parecen finalmente asimilarse a los pasos perdidos de la izquierda mexicana: fascinación por el vértice, burocratización, dinamitación de alianzas y sectores movilizados. En este punto, argumentás que el futuro de la experiencia que encabeza López Obrador depende de su capacidad de expresar una alianza que apueste a la construcción de una izquierda social. A una condensación en la que la obsesión no sea la fascinación por el vértice, sino la necesidad de desenvolverse en un plano basista y en la reconstrucción de una sociedad civil popular, democrática y participativa. Aunque no elegís contraponer Estado a lo social, sino una mirada que sea capaz de articular las instancias institucionales con una verdadera reconstrucción de las bases comunitarias y de la vida de las personas en sus espacios cotidianos. Para fomentar esta práctica desde una perspectiva crítica, ¿a qué referencias teóricas e intelectuales se podría recurrir? En Ensayos amargos sobre mi pais te retrotraés a la línea de masas del maoísmo mexicano, el cual, tras la experiencia novedosa de la Liga Comunista Espartaco encabezada por Revueltas y la represión de 1968, se lanzó a una política alejada de las estrategias tradicionales del PC, en pos de una acción orientada a construir con la comunidad y desde la comunidad. También volvés al clásico Cambiar el mundo sin tomar el poder de John Holloway (2002) y a esa discutida máxima de que no es desde el Estado y las mediaciones políticas desde donde se logra una transformación duradera en lo social.

- El gobierno de Morena tiene un filón en dirección hacia una izquierda social con nombre y apellido: es la secretaria de Bienestar, María Luisa Albores. Ella ha sido la coordinadora de Tosepan Titataniske, una organización campesina del norte de Puebla que asocia varios municipios con una producción diversificada y una democracia interna impresionante. Un verdadero laboratorio de lo que debe ser la reconstrucción social en lo social, con asesores intelectuales como Armando Bartra, Víctor Manuel Toledo, entre otros. Ellos tienen una propuesta, Toledo la llama regiones que caminan hacia la sustentabilidad (2014). Esa experiencia intelectual es nueva. Este tipo de pensadores no estaban en la izquierda regular. Son la nueva izquierda, aunque ellos no se llaman izquierda. Creo que más bien se llaman intelectuales sociales o intelectuales de mirada social. Si la experiencia de Albores o los libros maravillosos de Toledo pudieran meterse en la cabeza y en la dirección del nuevo gobierno sería realmente una reforma, la raíz de una nueva izquierda en la actualidad. Ellos son una parte de los asesores de López Obrador, aunque yo no he escuchado un planteamiento en esa dirección que sea aceptado, producido y legitimado desde el discurso de la Cuarta Transformación. Que 
aparezca una política social ligada a Albores y a todos ellos que diga que la Cuarta Transformación significa, entre otras cosas, el fortalecimiento de regiones sociales con plataformas participativas y con dineros que lleguen hasta abajo. Una propuesta de tipo economía social y solidaria que tiene ejemplos importantes en Sudamérica y algunas partes de Europa. Ese discurso todavía no aparece en el gobierno de López Obrador. Tiene que aparecer, si no, no tiene sentido que estén ahí esos grupos, a los que se liga mucho el ecologismo, el movimiento feminista y los movimientos indígenas. Ese es un paquete fuerte, muy social y muy anticultura mexicana tradicional de fascinación por el vértice y el poder central del Estado. Es la primera vez que vamos a voltear a ver las narcofosas y los decapitados, la construcción de regiones en serio. Ojalá que aparezca. Hay destellos interesantes.

- Cuando se hace referencia a una izquierda social, también aparece la cuestión del zapatismo. ¿Cómo evalúa las posiciones críticas del movimiento ante el gobierno de López Obrador?

- A mí me parece que el subcomandante Marcos, o como se llame, tiene regresiones a nuestra época de radicalismo universitario de los sesenta que ojalá no tuviera. La declaración del subcomandante Moisés sobre la instalación del ferrocarril del sureste, del Tren Maya, no sé cómo tomarla. Es una declaración de guerra: “en el momento que ustedes se metan a la selva con su tren, nosotros los paramos con el ejército”. Espérate, hay otro terreno de discusión sobre el asunto. Volver a la agresión militar a estas alturas y mantener a los caracoles completamente fuera de todo me parece una posición que ya no es acorde con la época. Armando Bartra tiene razón; dice que no se trata de que se ciñan a las políticas de la Cuarta Transformación. El zapatismo tiene una organización muy poderosa, incluso militar. Pueden trabajar con un pie adentro y un pie afuera. No les van a mochar el pie si se abre la posibilidad de que el financiamiento hacia los caracoles sea fluido. Tienen su organización territorial; tienen sus regiones. ¿Les da miedo acercarse al poder central o es rencor nada más? Los Acuerdos de San Andrés no se cumplieron, tienen toda la razón, pero el mundo cambia.

- Sos investigador emérito adscrito al Instituto de Investigaciones Sociales de la UNAM y coordinás el Equipo Pro-Regiones en esa misma casa de estudio, el cual se esfuerza por enlazar los saberes universitarios con problemas del entorno social en distintos ámbitos de México. Desde esta experiencia, sostenés que no existe una condensación conceptual en el espectro de las ciencias sociales de nuestra época, donde prevalece la fragmentación, la hiperespecialización y la distancia con los problemas sociales concretos. Desde tu punto de vista ęcómo es posible afianzar una unidad no excluyente en las ciencias sociales que sea generadora de consensos intelectuales? ¿Sigue siendo productiva la idea de movimientos sociales?

- Ahorita vengo de una conferencia sobre movimientos sociales y me parece que la concepción de movimientos sociales oculta la idea de reconstrucción social desde lo social. La oculta terriblemente porque busca las rupturas del orden y pone el acento en las pequeñas burbujas que estallan. Esas pequeñas burbujas, como YoSoy132, estallan y desaparecen. Entonces, ver la sociedad a través de los lentes de los movimientos sociales ya es una especie de deformación de la sociología. Lo está diciendo alguien que se formó con el concepto de movimiento social. En mi generación teníamos la idea de revolución que transformamos en movimiento social y luego en el concepto de nuevos movimientos sociales. Pero no dejamos la tarabilla de ver a la sociedad como movimiento, en el sentido de abandonar lo de ahora para irnos a otra cosa. Hay una discusión no dada todavía, pero que se está perfilando, en la que la idea de movimiento social ya nos está estorbando. Quizá más que hablar de movimientos sociales, tenemos que usar el concepto de reconstrucción social a partir de experiencias definidas territorialmente. La idea griega, española e italiana del norte, que es la confederación de municipalidades que se salen del stream comercializador-globalizador -y que tratan a través de su colaboración, de generar una economía y una propuesta anticapitalista, pero no contracapitalista-, es un proyecto anticapitalista, sedimentador de lo social, totalmente pacífico, sin la idea de movimiento porque no va a ir a ninguna parte, sino que busca sedimentar en el mismo territorio. Los griegos están muy avanzados en ese asunto, como Takis Fotopoulos. Ellos son los hijos de Corneluis Castoriadis, un gran pensador de este tipo de democracia. Ahí existe un filón, ¿pero cómo atraca este barco en tierras mexicanas? Hay que buscar 
alternativas teóricas y prácticas contra la globalización capitalista voraz, e indagar, como Toledo, ejemplos que caminen hacia la sustentabilidad.

- Pero desde estas problematizaciones, ¿creés posible afianzar una unidad no excluyente en las ciencias sociales que exprese consensos intelectuales? En tus trabajos elegís retomar y enlazar autores diversos como Pierre Bourdieu, Boaventura de Sousa Santos, Immanuel Wallerstein y Alain Touraine.

- Te confieso, no es fácil saber dónde están los apoyos de una idea así, tanto en la práctica como en nombres y apellidos concretos. Holloway sigue siendo un punto de discusión interesante. El movimiento feminista y las mujeres. No como movimiento; fíjate qué traición a mí mismo, dije "movimiento de las mujeres". Yo diría la actuación, la sedimentación, el empoderamiento de las mujeres y su planteamiento en términos de sociedad-ecología-mujer es un filón poderosísimo y que atrae a una parte muy importante de una sociedad como esta mexicana de hoy y aquí. Veo por ahí una esperanza fuerte. Los Derechos Humanos también, pero de repente eso se traslada muy fácil a la idea de tránsito a la democracia y las instituciones de la democratización. Hay que tener cuidado con esa salida a lo institucional. Por eso me parece con más potencia la unión de términos como ecología-mujer-sociedad-economía solidaria. Y creo que es a través de las mujeres que se va a empezar a oír mejor. Si dices economía solidaria no suena. Si dices el rol de las mujeres en una sociedad tan violenta como nuestro país, ese es el altoparlante que se está escuchando y va a oírse con mucha más fuerza.

- Hace once años publicaste Resistencia y cambio en la UNAM (2008),donde analizás en perspectiva histórica las batallas por la autonomía y la gratuidad universitaria. Desde tu visión, ęcuáles son las principales demandas y problemáticas que tiene que enfrentar la UNAM en el contexto político actual?

- Yo tengo la impresión de que nuestra universidad está completamente desvirtuada. No concibo que un profesor joven gane 70 pesos la hora y que un profesor como yo con 40-45 años de servicio posea un salario tan elevado como el que tengo. Gano mucho dinero. Perdón por decirlo de esta manera, pero es para decirlo claro. Un ayudante mío que colabora en Pro Regiones gana 70 pesos la hora de clase a grupos, aparte de lo que le costó prepararla o calificar. Qué le pasa a esta universidad para hacer eso. Es increíble el despilfarro de dinero que hay en las altas esferas de la UNAM. Ahí sí tenemos que entrar en la Cuarta Transformación y necesitamos una reforma universitaria en serio. No es posible que tengamos salones, salones y salones vacíos, y que con 90 investigadores de primera en este instituto sólo poseamos 60 alumnos sumados entre todos. i¿Qué es esto?! Qué absurdo tan grande, con un presupuesto de $40 \mathrm{mil} \mathrm{millones} \mathrm{de} \mathrm{pesos.} \mathrm{No} \mathrm{es} \mathrm{cualquier} \mathrm{tontería,}$ ¿no? Con Morena se van abrir debates; en el Consejo Nacional de Ciencia y Tecnología (CONACYT) ya estallaron. Cuando se dieron cuenta de que desde el organismo se estaba financiando a empresas privadas y a empresas trasnacionales para que hiciera investigación la Nestlé, surgió la pregunta: ¿Por qué el dinero de México tiene que estar orientado a financiar a las trasnacionales que explotan al país? Hay unos errores y deformaciones tan brutales adentro de una institución como CONACYT que es muy bueno que surjan este tipo de debates. También en la universidad. Si tenemos que bajar a la mitad del salario, ni modo. Pero no podemos seguir con estos absurdos.

\section{BibLiografía}

Garretón, M. A. y Martínez, J. (1985). Biblioteca del movimiento estudiantil. Chile: Ediciones Sur

González de Alba, L. (1971). Los días y los años. México: Era

Holloway, J. (2002). Cambiar el mundo sin tomar el poder. México: Herramienta Ediciones

Poniatowska, E. (1971). La Noche de Tlatelolco. México: Era

Revueltas, J. (1969). El Apando. México: Era

Revueltas, J. (1962). Ensayo sobre un proletario sin cabeza. México: Ed. Liga Leninista Espartaco

Revueltas, J. (2016) [1978]. México 68. Juventud y revolución. México: Era 
Sarlo, B. (2001). La batalla de las ideas. Buenos Aires: Ariel

Terán, O. (1991). Nuestros años sesentas. Buenos Aires: Punto Sur

Toledo, V. M. y Ortíz-Espejel, B. (2014). México, regiones que caminan hacia la sustentabilidad. México: Universidad Iberoamericana Puebla

Touraine, A. (1970) [1969]. El movimiento de mayo o el comunismo utópico. Buenos Aires: Signos

Womack Jr., J. (1969). Zapata y la revolución mexicana. México: Siglo XXI

Zermeño, S. (2018). Ensayos amargos sobre mi país. Del 68 al nuevo régimen, cincuenta años de ilusiones. México: Siglo XXI

Zermeño, S. (1978). México: una democracia utópica. El movimiento estudiantil del 68. México: Siglo XXI

Zermeño, S. (2008). Resistencia y cambio en la UNAM. México: Océano

\section{Notas}

1 Los trabajos de Revueltas en torno a la universidad fueron compilados póstumamente en México 68. Juventud y Revolución (1978). 